\title{
Clinical Establishments Registration and Regulation System (CERRS) in India
}

\author{
Mahima Singh ${ }^{1}$, Rakesh Kumar Singh ${ }^{2}$, MPS Bhatia ${ }^{3}$
}

\begin{abstract}
The Clinical Establishments Act 2010, as passed by Parliament provides for Registration and Regulation of the clinical establishments with a view to prescribe minimum standards of facilities and services which may be provided by the Clinical Establishments, so that mandate of article 47 of the constitution can be fulfilled. The Clinical Establishments Registration and Regulation System (CERRS) Project enables on line registration and approval. The main challenges in implementation of the project are adoption of the Act by all the States and those who have adopted, the implementation be emphasized in some specific period by the regulating authorities. Some limitations for online registration/renewal of Clinical Establishments have been observed and software needs to be upgraded. In addition, for wider and effective implementation, there should be regular dissemination of information and stakeholders' participation. The project will pave the way in improving public health for the citizens of the country in due course of time.
\end{abstract}

Keywords: Clinical Establishment Act, Online Registration Process, Clinical Establishment, District Registration Authority

\section{Introduction}

The Health System in India is a fragmented mix of public, private and voluntary sectors that provides promotive, preventive, diagnostic and curative health services in Allopathic and various indigenous systems of medicine. While there are nearly 180,000 public health facilities across India, there is no robust data available for the private health sector which ranges from single doctor clinics to diagnostic and imaging centres, multi-speciality polyclinics and corporate hospitals.

A need for central legislation to register and regulate clinical establishments in the country was felt, as Article 47 of the Constitution of India mandates improvement in public health. Private health sector has exhibited unprecedented growth, but has remained largely unregulated ${ }^{[1], ~[2] . ~ M o s t ~ p e o p l e ~ i n ~ I n d i a ~ u s e ~ p r i v a t e ~ h e a l t h ~ s e r v i c e s ~ a n d ~ f a c i l i t i e s ~ b u t ~ l a c k ~}$ both information about them and any control over them ${ }^{[3]}$. Majority of States in India have either no legislations or have legislations which are not comprehensive and thus have remained ineffective. In some states, regulatory legislations exist, but have not been implemented ${ }^{[4]}$. Concerns on how to improve health care quality continue to exist ${ }^{[5]}$. There has been no systematic collection of information from private health care providers.

Project CERRS has been undertaken to implement Clinical Establishments Act 2010 through online web application 'Clinical Establishment Registration and Regulation System' (CERRS) and can be accessed through URL www.clinicalestablishments. gov.in. In this paper we have reviewed the implementation of the CERRS Project and proposed the improvement required in effective adoption and implementation of the CERRS Project.

${ }^{1}$ BE, Netaji Subhas Institute of Technology, New Delhi, India.

${ }^{2}$ Department of Information Technology, Indira Gandhi Delhi Technical University for Women, New Delhi, India.

${ }^{3}$ Department of Computer Engineering, Netaji Subhas Institute of Technology, New Delhi, India

Correspondence: Mahima Singh, Netaji Subhas Institute of Technology, New Delhi, India.

E-mail Id: ms.mahima26@yahoo.com

Orcid Id: http://orcid.org/0000-0001-7310-9806

How to cite this article: Singh M, Singh RK, Bhatia MPS. Clinical Establishments Registration and Regulation System (CERRS) in India. Int J HealthCare Edu \& Med Inform 2017; 4(2): 15-19.

Digital Object Identifier (DOI): https://doi.org/10.24321/2455.9199.201708

ISSN: 2455-9199 
Section 2 of the paper provides brief overview of the Clinical Establishments Act 2010, section 3 discusses about the automation process for CERRS and section 4 discusses the issues and challenges and the conclusion is give in section 5 .

\section{Overview of Clinical Establishments ACT 2010}

In the above background, the Clinical Establishments Act 2010 was passed by Parliament in August 2010. The Act provides for registration and regulation of the clinical establishments with the purpose of standardization of health care facilities based on scope of services provided by the clinical establishments and ensuring standardization of treatment ${ }^{[6]}$. The Act as on date has been adopted in the following 10 States and 6 Union Territories (UTs):

States are Arunachal Pradesh, Himachal Pradesh, Sikkim, Mizoram, Bihar, Jharkhand, Uttar Pradesh, Uttarakhand, Rajasthan and Assam. However States of Uttar Pradesh, Uttarakhand and Bihar have not yet implemented the Act.

Union territories are Andaman \& Nicobar Islands, Daman \& Diu, Dadra \& Nagar Haveli, Puducherry, Chandigarh and Lakshadweep.

The Act is applicable to both therapeutic and diagnostic clinical establishments from public and private sectors, of all recognized systems of medicine including Indian systems of medicine. The only exception is clinical establishments run by the Armed forces which are not regulated under this Act. However, for the Act to be applicable in a State, it has to be adopted by the concerned State Government by passing a resolution in the state legislatures in this regard. The National Health Policy 2017 emphasises on advocacy for adoption of the Act by other states also ${ }^{[7]}$. The Vision 2020 document also highlights key role of regulation in health sector ${ }^{[8]}$.

The Act provides for a multi-member body namely 'National Council for Clinical Establishments' at National level which is responsible for categorization of clinical establishments, prescribing category wise minimum standards, compilation and publication of a National Register of clinical establishments and to collect the information and statistics from clinical establishments. The implementation of the Act is with the authorities of State Government namely a 'State Council for Clinical Establishments' at State level and a 'District registering authority' in each district. The definition of Clinical Establishment as per the Act is broadly stated in table 1.

Table 1.Definition of Clinical Establishment

According to the Clinical Establishments Act, $2010^{6}$, Clinical Establishment is defined as a hospital, nursing home including maternity home, dispensary, clinic or an institution by whatever name called that offers services, facilities requiring diagnosis, treatment or care for illness, injury, deformity, abnormality or pregnancy in any recognised system of medicine or a place established as an independent entity or part of an establishment in connection with the diagnosis or treatment of diseases where laboratory investigations like pathological, bacteriological, genetic radiological, chemical, biological investigations are usually carried out and includes a clinical establishment owned, controlled or managed by

- $\quad$ the Government or a department of the Government;

- $\quad$ a public or private trust;

- a registered Government or Non- Government corporation including a society

- a local authority; and

- a single doctor

\section{Project CERRS}

The main purpose of project was to design an on-line web portal of Ministry of Health \& Family Welfare for registration of clinical establishment and approval of the registration by the authority. The web based e-learning content for this purpose has also been developed for the benefit of the users from clinical establishments and others.

The objectives of CERRS are broadly stated in table 2 . 
Table 2.Objectives of CERRS

- To provide an online and efficient system for facilitating registration of all Clinical establishments in the country, so as to establish digital registry of Clinical Establishments at National, State and District level.

- A robust user friendly Web Application, available 24X7 and would comply with user accessibility guidelines.

- Health being matter of state, at present only the states and union territories, where the Act is applicable would participate.

- $\quad$ Post acceptance from more states, the application has an option to include additional fields in the Registration form.

\section{Scope of project}

\section{Online registration}

It covers a number of components and processes related to registration of clinical establishments with workflow for approval or rejection of registration. The pdf file of registration certificate can be downloaded. The registration certificate can be surrendered, cancelled or extended as per requirements. The process of registration and approval has been integrated with a dedicated website namely http://clinicalestablishments.gov.in and also with SMS and E-MAIL gateway.

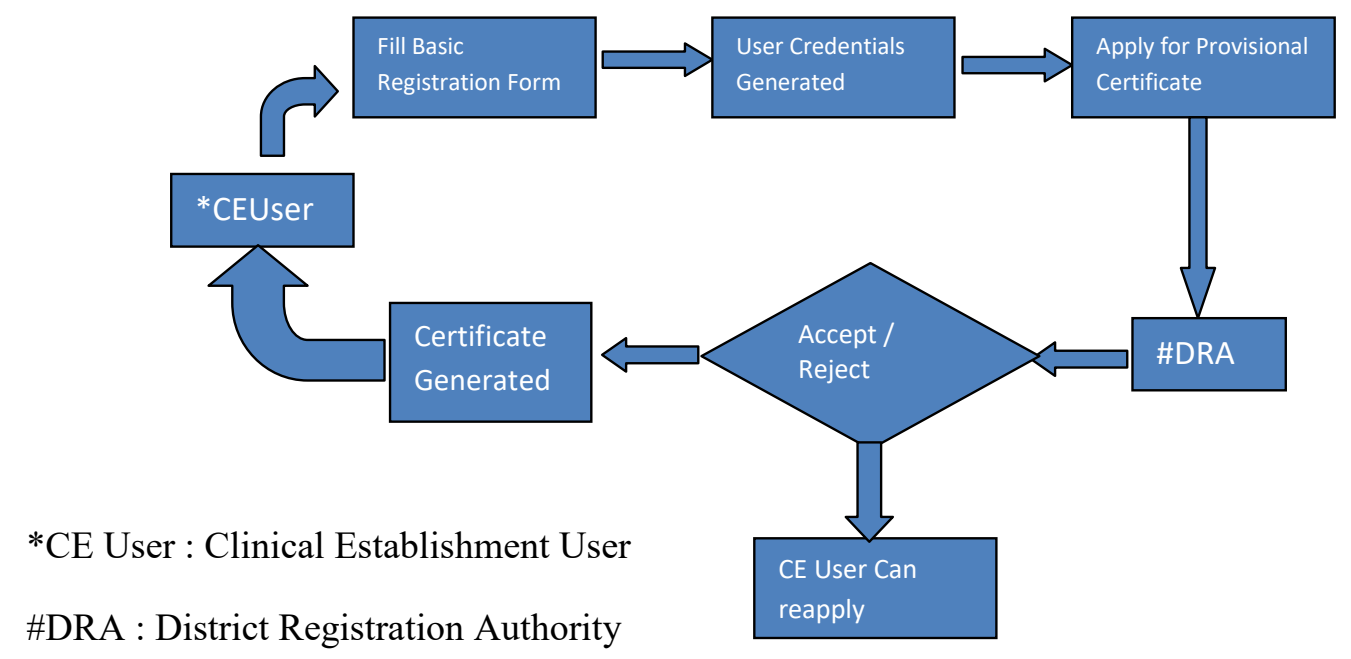

Figure 1.Registration Process

\section{Digital Registry}

Digital Registers of clinical establishments are generated and automatically compiled for District, State and National level to assist in various roles of authorities at these levels. The entire data related to clinical establishments collected, is in public domain.

\section{Search module}

Search module has scope to search for a clinical establishment by parameters like its location, type, ownership etc.

\section{Module for Feedback}

Module for receiving feedback/complaint against clinical establishment has been added.

\section{Report and Analysis}

A report and analysis module has been incorporated to generate the following reports -

- Dashboard for the authority

- Customized reports

- Visual analytic reports for different operational attributes as required by the Authority

\section{Training to district, state and national users}

A dedicated separate training website has been operationalized to minimize entry of junk data. User manual and a web-based training module has been added to explain the registration process as defined under law.

\section{Unique Registration number for every clinical establishment}

Every clinical establishment registered through website is assigned a unique 10 digit number identifying the State or Union Territory (UT) to which clinical establishment belongs, the specific district in which it is located and serial number with in that district 


\section{Current Status of Registration in the States/UTs}

As on 12.11.2017, 13423 Clinical Establishments have registered online, forming part of the Digital National Register as indicated in table 3 and 1951 have registered offline.

Table 3.State or UT wise online registered clinical establishments as on 12-11-2017 ${ }^{[6]}$

\begin{tabular}{|c|c|c|c|c|c|c|c|c|c|}
\hline State / UT & Allopathy & Ayurveda & Unani & Siddha & Homoeo -pathy & Yoga & Natura -pathy & Sowa Rigpa & Total* \\
\hline $\begin{array}{l}\text { Andaman } \\
\text { \& Nicobar } \\
\text { Islands (Ut) }\end{array}$ & 120 & 20 & 1 & 2 & 28 & 3 & 2 & 0 & 138 \\
\hline $\begin{array}{c}\text { Arunachal } \\
\text { Pradesh }\end{array}$ & 11 & 1 & 0 & 0 & 2 & 0 & 0 & 0 & 11 \\
\hline Assam & 2346 & 459 & 13 & 10 & 118 & 26 & 4 & 0 & 2429 \\
\hline $\begin{array}{c}\text { Chandigarh } \\
\text { (Ut) }\end{array}$ & 384 & 35 & 0 & 0 & 20 & 3 & 1 & 0 & 415 \\
\hline $\begin{array}{c}\text { Dadra } \\
\text { \& Nagar } \\
\text { Haveli (Ut) }\end{array}$ & 124 & 36 & 1 & 0 & 36 & 0 & 1 & 0 & 182 \\
\hline $\begin{array}{c}\text { Daman \& } \\
\text { Diu (Ut) }\end{array}$ & 119 & 31 & 1 & 0 & 52 & 3 & 0 & 0 & 174 \\
\hline $\begin{array}{l}\text { Himachal } \\
\text { Pradesh }\end{array}$ & 3742 & 2164 & 130 & 28 & 168 & 52 & 56 & 13 & 5648 \\
\hline Jharkhand & 3858 & 149 & 33 & 3 & 124 & 18 & 14 & 0 & 3983 \\
\hline $\begin{array}{l}\text { Puducherry } \\
\text { (Ut) }\end{array}$ & 265 & 19 & 0 & 14 & 9 & 1 & 1 & 0 & 271 \\
\hline Rajasthan & 160 & 23 & 9 & 0 & 15 & 8 & 4 & 0 & 172 \\
\hline Total & 11129 & 2937 & 188 & 57 & 572 & 114 & 83 & 13 & 13423 \\
\hline
\end{tabular}

${ }^{*}$ The difference in total of row and column is due to the fact that a Clinical Establishment may have more than one system of medicine operational.

\section{Benefits of the CERRS}

The Clinical Establishments' Registration and Regulation System provides access to latest information - for users wherever they are located. The authorized district, state and national users have access to all information authorized for their level. The implementation reduces business costs with less time is spent talking to clinical establishment over the phone/email/paper mail. It eliminates printed materials. It allows clinical establishments to update their own details. The centralized data is secure and easy to backup with technical support provided by National Informatics Centre, Government of India. The services are available 24 hours a day, 7 days a week with support of training material available online that can be used at user's own time and pace.

\section{Issues and Challenges}

The main challenge observed in implementation of the system is adoption of the Clinical Establishments Act by only few States and Union Territories. Health being a State subject, the provisions of the Act become applicable only after its adoption by the State. The States where the Act has been implemented have been slow. Although the system is backed by robust security system of Government of India, still because of multiple users, periodic audit from security point of view are essential. In some of the states, the capacity for online registration in districts is low because of poor internet access and computer literacy especially in north-eastern part of the country. In such places, the online registration could not be operationalized. There is also poor dissemination of information to stakeholders. There are misconceptions among those running clinical establishments and professional medical associations that they may be monitored, if they join the national registration and regulatory system. There is also fear of litigations against them. These misconceptions can be removed by reassurance from Government authorities and explaining true purpose of Act. It was also noted that in some cases, quacks also got themselves registered through online process by entering wrong information. There is specific challenge with respect to compliance of standards of health personal; both medical and paramedical. Some Software inadequacies for online registration/renewal of Clinical Establishments have been noted in the form of technical snags which made it difficult to maintain updated records of registered facilities. For example there were no provisions in the software for transferring the ownership of a Clinical Establishment. 


\section{Suggested Way Forward}

There is a need to upgrade the software to incorporate automatic registration in a specific Application Format for ensuring the compliance. For verification of qualification related data of health personnel working in a clinical establishment, the software may be linked with database of respective regulatory councils like Medical Council of India, Dental Council of India, Indian Nursing Council, Pharmacy Council of India etc. The facility for uploading documents by the Clinical Establishment with application form may be added to enhance verification process. The key processes in registration and approval needs to be digitally signed by authorized user. Regular timely security audits of software need to be carried out. The required training should be imparted to all users. For wider and effective implementation, there should be regular dissemination of information to stakeholders and their participation should be ensured to increase its acceptability and implementation. The whole process of registration and regulation should incorporate greater automatism to minimize physical interaction between clinical establishment user and regulator.

\section{Conclusion}

The Clinical Establishments Registration and Regulation System is a promising digital tool to improve healthcare and availability of health information in India. However streamlining the automation process, dissemination of correct information and stakeholder participation shall contribute to its greater acceptability and effectiveness. This shall go a long way in improving public health for the citizens of the country.

\section{Conflict of Interest: None}

\section{References}

1. Afifi NH, R Busse Harding A. "Regulation of health services. Private participation in health services". The World Bank, Washington,. DC. 2003; pp: 219-334.

2. Kwon S. Thirty years of national health insurance in South Korea: lessons for achieving universal health care coverage. Health policy and planning 2009; 24(1): 63-71.

3. Nandraj S. Private healthcare providers in India are above the law, leaving patients without protection. BMJ 2015; 350: h675.

4. Sheikh K, Saligram PS, Hort K. What explains regulatory failure? Analysing the architecture of health care regulation in two Indian states. Health policy and planning. 2015; 30(1): 39-55.

5. Rao P. The private health sector in India: a framework for improving the quality of care. ASCI Journal of Management 2012; 41(2): 14-39.

6. The Clinical Establishments Act; accessed through webportal www.clinicalestablishments.gov.in.

7. The National Health Policy 2017- Govt of India. Ministry of Health and Family Welfare. New Delhi, MoHFW 2017: 22.

8. Srinivisan R. Health Care in India-Vision 2020. New Delhi, India: Government of India, Planning Commission of India 2010.

Date of Submission: 2017-10-21

Date of Acceptance: 2017-10-25 